\title{
Stability of a Dosage Form and Forced Degradation Studies
}

\section{Safila Naveed*, Sania Basheer and Fatima Qamar}

Jinnah University for Women, Pakistan

\begin{abstract}
The stability of the pharmaceutical formulation during its entire shelf life in its final packaging is an important matter. Stability study does not only cover the physiochemical aspects of the drug but also explains the safety and efficacy of the product during its entire shelf life. Force degradation studies are the studies in which stress conditions or accelerated conditions are provided to the drug in bulk or product. For the development of stability indicating methods especially when insufficient information is accessible about degradation products and to obtain information about the degradation pathways and degradations products that might affect during storage conditions forced degradation studies are performed. Forced degradation studies help to facilitate pharmaceutical development, manufacturing, production and packaging where knowledge of chemical behavior can be used to improve drug product. An FDA and $\mathrm{ICH}$ regulatory body portrays the layout of these stability limitations for the stability and degradation point of view.
\end{abstract}

Keywords: Stability; Force degradation studies; Safety and efficacy; Shelf life; Pharmaceutical formulation

\section{Introduction}

The stability of the pharmaceutical formulation during its entire shelf life in its final packaging is an important matter [1]. Any change in the physical, chemical, micro biological and therapeutic properties in any component of the drug whether it is active or excepient will lead to the un-stability [2-4]. Therefore due to this reason during designing and development of new dosage form special consideration is given that both excipients and active should remain stable and retain their properties during entire their shelf life. And such product must

- Contain not less than $90 \%$ of its therapeutic activity.

- Contain at least $90 \%$ of its stated concentration.

- Contain an effective concentration of added preservatives.

- Have no visible change, that is, discoloration, precipitation and development of off odors.

- Contain no toxicity and irritancy.

In United stated Pharmacopeia (USP) definition of stability is given as "the ability of a product to retain its characteristics that it possessed during its manufacturing (physical, chemical, micro biological, therapeutic properties) within specified limits throughout its period of storage and use" [5].

According to ICH guidelines pharmaceutical stability testing defined as "systematic experiments conducted on pharmaceutical products to understand and provide evidence how the quality of a drug product varies under the influence of variety of environmental factors such as temperature, humidity, and light and to set re-test period for the drug or a shelf life for the drug product and recommend good storage condition" [6].

\section{Stages of stability studies}

Stability studies are conducted at every stages of the drug life cycle from $1^{\text {st }}$ stages of product development to late stage follow up studies. There are 6 different stages:

Stage 1: Early stage i.e., stress and accelerated testing with drug substances.

Stage 2: Stability on pre-formulation lotes/batches.
Stage 3: Stress test done on scale up batches.

Stage 4: Accelerated and long term testing for registration purposes.

Stage 5: Enduring stability testing.

Stage 6: Follow up studies.

\section{Importance of stability studies}

The stability study that we done play a significant role in the lifecycle of a successful pharmaceutical formulation and product. Stability study does not only cover the physiochemical aspects of the drug but also explains the safety and efficacy of the product during its entire shelf life [7-11].

\section{Factors influencing drug stability}

Moisture: Water soluble solid dosage form will dissolve when comes in contact with any moisture layer and leads to create many physical and chemical changes in the dosage leading it to lose its properties [12].

Excipients: Some excipients like starch and povidone have high water contents and affect the stability by increasing the water content of the formulation. Sometimes chemical interactions between the excipients and the drug can occur and lead to decrease in stability [13].

Temperature: Changes in temperature have sometimes drastic effect on the stability of drug. Increase in temperature usually causes increase in hydrolysis rate of drugs. The effect of temperature on stability described by Arrhenius equation [14].

pH: $\mathrm{pH}$ has great effect on the rate of decomposition of drugs that are hydrolyzed in solution. To minimize this effect drug are formulated at the $\mathrm{pH}$ of maximum stability using buffers [15].

*Corresponding author: Naveed S, Faculty of Pharmacy, Jinnah University for Women, Karachi, Pakistan, Tel: 00923002621917; E-mail: safila117@yahoo.com

Received November 25, 2016; Accepted May 05, 2016; Published May 12, 2016

Citation: Naveed S, Basheer S, Qamar F (2016) Stability of a Dosage Form and Forced Degradation Studies. J Bioequiv Availab 8: 191-193. doi:10.4172/ jbb.1000292

Copyright: ( 2016 Naveed S, et al. This is an open-access article distributed under the terms of the Creative Commons Attribution License, which permits unrestricted use, distribution, and reproduction in any medium, provided the original author and source are credited. 
Citation: Naveed S, Basheer S, Qamar F (2016) Stability of a Dosage Form and Forced Degradation Studies. J Bioequiv Availab 8: 191-193. doi:10.4172/jbb.1000292

\begin{tabular}{|c|c|c|c|}
\hline \multicolumn{3}{|c|}{ Drug Substance } & Drug Product \\
\hline Conditions & Solid & Solution/Suspension & Solid (Tablet capsules, blends) \\
\hline Acid/Base & - & $\checkmark$ & - \\
\hline Oxidative & $X$ & $\checkmark$ & $\checkmark$ \\
\hline Photo stability & $\checkmark$ & $X$ & $\checkmark$ \\
\hline Thermal & $\checkmark$ & - & $\checkmark$ \\
\hline Thermal, humidity & $\checkmark$ & - & $\checkmark$ \\
\hline
\end{tabular}

$\checkmark$ : Recommended; X: Optional, suggested for some compounds

Table 1: General protocol for forced degradation studies (stress studies) of a drug substance and drug product.

Oxygen: The presence of oxygen promotes oxidation in some drugs. Drugs which have higher rate of decomposition when exposed to oxygen are stabilized by replacing the oxygen in the storage container with nitrogen or carbon dioxide [16-17].

Light: Certain drugs are photosensitive and their rate of decomposition enhances when exposed to light. Their susceptibility can be tested by comparing it stability when exposed to light to that when stored in dark. Photosensitive drugs should be stored in amber glass containers and should be kept in dark [18].

\section{Force degradation studies}

Force degradation studies define as the studies in which stress conditions or accelerated conditions are provided to the drug in bulk or product for two reasons i.e., to when developing stability indicating methods specially when very little information is available about degradation products and secondly to get information about the degradation pathways and degradations products that might effect during storage conditions [19-21].

Forced degradation studies help to facilitate pharmaceutical development, manufacturing, production and packaging where knowledge of chemical behavior can be used to improve drug product [22-24].

\section{Degradation studies of a drug substance}

FDA demands the following at the time of registration [25-35].

1. Stressing the drug substance in solution or suspension at alkaline and acidic $\mathrm{pH}$ and under oxidation conditions.

2. Stressing the solid bulk drug substance at temperature and temperature + humidity conditions in excess of accelerated conditions.

3. Stressing the drug substance photolytically in the solid state or in solution excess.

4. Demonstration of the specificity of stability indicating methods with forced degraded samples.

5. Full characterization of the degraded products by means of NMR, mass spectrometry(MS), UV analysis

6. Chemical and physical properties of the degradation products, if available.

7. The mechanism and kinetics of degradation products formed, if available [1-6].

\section{Conclusion}

Conclusion will be discussed in Table 1

\section{References}

1. Khalil M (2008) Drugs Stability Study - A Review

2. Yoshioka S, Stella VJ (2000) Stability of drugs and dosage forms. New York: Kluwer Academic/Plenum Publishers pp: 139-150.

3. (2006) Rockville MD, United States Pharmacopeia (USP), Stability considerations in dispensing practices 1191.

4. Carstensen JT (2000) Solution Kinetics; Kinetic pH profiles; Oxidation in solution; Catalysis, Complexation, and Photolysis, in Carstensen JT, Rhodes CT, (eds.), Drug Stability, Principle and Practice, $3^{\text {rd }}$ (edn.), Marcel Dekker, New York pp: 19-143.

5. David A, Alexander TF (2008) Fast track: Physical Pharmacy, 1 ${ }^{\text {st }}$ (edn.) London, Pharmaceutical Press p: 29

6. Kim HB (2009) Handbook of Stability Testing in Pharmaceutical Development $1^{\text {st }}$ (edn.), New York, Springerlink.

7. Reynolds DW, Facchine KL, Mullaney JF, Alsante KM, Hatajik TD, et al. (2002) Conducting forced degradation studies. Pharmaceutical Technology pp: 48-56.

8. Baertschi SW, Alsante KM, Reed RA (2011). Pharmaceutical stress testing predicting drug degradation. CRC Press.

9. Alsante KM, Martin L, Baertschi SW (2003) A stress testing benchmarking study. Pharmaceutical Technology 27: 60-73.

10. Matthews BR (1999) Regulatory aspects of stability testing in Europe. Drug Dev Ind Pharm 25: 831-856.

11. Singh S, Bakshi M (2000) Stress test to determine inherent stability of drugs Pharm Technol 4: 1-14

12. Bakshi M, Singh S (2002) Development of validated stability-indicating assay methods--critical review. J Pharm Biomed Anal 28: 1011-1040.

13. Singh S, Junwal M, Modhe G, Tiwari H, Kurmi M, et al. (2013) Forced degradation studies to assess the stability of drugs and products. TRAC Trends in Analytical Chemistry 49: 71-88.

14. Tollefson AE, Hermiston TW, Lichtenstein DL, Colle CF, Tripp RA, et al. (1998) Forced degradation of Fas inhibits apoptosis in adenovirus-infected cells. Nature 392: 726-730.

15. Marin A, Barbas C (2004) LC/MS for the degradation profiling of cough-cold products under forced conditions. Journal of Pharmaceutical and Biomedical Analysis 35: 1035-1045.

16. Brümmer DH (2011) How to approach a forced degradation study. Technical Bulletin. Life Sci 31.

17. Singh R, Rehman ZU (2012) Current trends in forced degradation study for pharmaceutical product development. Journal of Pharmaceutical Education and Research 3: 54

18. Sanjay B, Singla D, Sakhuja N (2012) Stability testing of pharmaceutical products. Journal of Applied Pharmaceutical Science 2: 129-138.

19. Alsante KM, Ando A, Brown R, Ensing J, Hatajik TD, et al. (2007) The role of degradant profiling in active pharmaceutical ingredients and drug products. Adv Drug Deliv Rev 59: 29-37.

20. Lucas $\mathrm{TI}$, Bishara RH, Seevers RH (2004)A stability program for the distribution of drug products. Pharmaceutical Technology 28: 68-73. 
Citation: Naveed S, Basheer S, Qamar F (2016) Stability of a Dosage Form and Forced Degradation Studies. J Bioequiv Availab 8: 191-193. doi:10.4172/jbb.1000292

21. Bouligand J, Storme T, Laville I, Mercier L, Oberlin O, et al. (2005) Quality control and stability study using HPTLC: applications to cyclophosphamide in various pharmaceutical products. J Pharm Biomed Anal 38: 180-185.

22. Naveed S, Shafiq A, Khan M, Jamal M, Zafar H, et al. (2014) Degradation Study of Available Brands of Metformin in Karachi Using UV Spectrophotometer. J Diabetes Metabolism 5: 328.

23. Naveed S, Naseem Y, Samie S, Khan S, Siddiqui S, et al. (2014) Degradation study of five different brands of ciprofloxacin using UV-visible spectrophotometer and their comparitive study. IRJP 5: 189-190.

24. Naveed S, Waheed N, Nazeer S (2014) degradation studies of ampicillin in API and formulations. J App Pharm 6: 314-321

25. Naveed S, Waheed N, Nazeer S (2014) Degradation study of metronidazole in active and different formulation by UV spectroscopy $\mathrm{J}$ Bioequiv Availab 6: 124-127.

26. Naveed S, Waheed N, Nazeer S, Qamar F (2014) Degradation study of gentamicin by UV spectroscopy Chemistry and Applications 1: 36-39.

27. Naveed S, Qamar H, Jawaid W, Bokhari U (2014) Degradation study of six different brands of doxycycline using UV spectrophotometer. The Global Journal of Pharmaceutical Research 3: 1978-1984.
28. Naveed S, Uroog S, Waheed N (2014) Degradation studies of different brands of moxifloxac in available in the market. IJCPR pp: 110-116.

29. Naveed S, Nazeer S, Waheed N (2014) Degradation study of meloxicam by UV Spectroscopy British Journal of Research 1: 105-112.

30. Dilshad H, Naveed S, Sarwar G (2014) Effects of external contributing factor temperature on hardness, friability and degradation on packaged Atrovastatin tablets formulation. Journal of Pharmacy and Pharmaceutical Sciences 2: 77-82.

31. Naveed S, Qamar H (2015) Relative degradation study of local vs multinatational brand of Diltazem using UV spectrophotometer. American Journal of Pharmacology and Pharmacotherapeutics 2: 010-018.

32. Naveed S, Qamar H, Jawaid W, Bokhari U (2014) Effect of acid, base and time on different brands of Glimepiride, Open Access Library Journal 1: 1-5.

33. Naveed S, Qamar F, Zainab S, Sarwar G, Usmanghani K, et al. (2015) Effect of Acidic and Alkaline Medium on Fexofenadine brands using UV Spectrophotometer. Can J App Sci 5: 100-104.

34. Naveed S, Qamar F, Zainab S (2015) Effect of Acid Base on different Brands of Sitagliptin by using UV Spectrophotometer. JIPBS 2: 115-118.

35. Naveed S, Qamar F, Zainab S (2015) Effect of Acidic and Basic Medium on Celecoxib by UV Spectroscopy. J Nutr Disorders Ther 5: 166. 